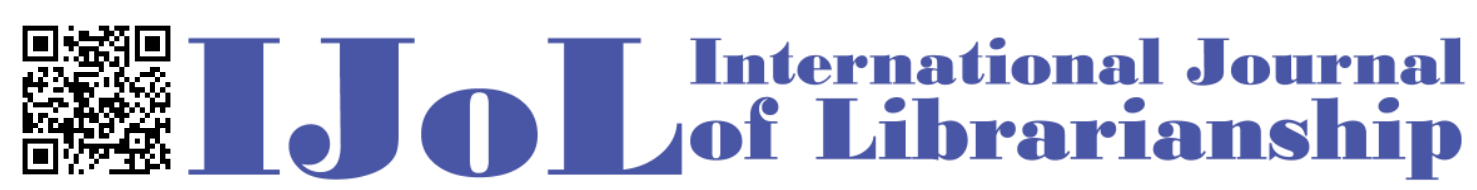

ISSN: 2474-3542 Journal homepage: http://journal.calaijol.org

\title{
Establishing a Vibrant Information Literacy Program in the Absence of Curriculum Mandate: A Case Study
}

\author{
Lijuan Xu
}

\begin{abstract}
:
This article describes how the Skillman Library at Lafayette College uses internal grants to successfully integrate information literacy into upper-level courses. There is a general consensus among faculty grant recipients that integrating information literacy in their courses not only improves students' skills as consumers of information but also helps students understand how scholars have answered questions in their particular field, and how the students themselves can contribute to the creation of knowledge. Due to their positive grant course experience, faculty members continue to build information literacy in their courses and are advocates for information literacy. The grant program created a culture of information literacy at Lafayette College and led to further pedagogical and curricular changes. It has also allowed librarians to venture into new territories such as studio art and expanded our involvement from guest lecturers to co-designing and coteaching courses.
\end{abstract}

To cite this article:

$\mathrm{Xu}, \mathrm{L}$. (2017). Establishing a vibrant information literacy program in the absence of curriculum mandate: A case study. International Journal of Librarianship, 2(2), 84-91. https://doi.org/10.23974/ijol.2017.vol2.2.36

To submit your article to this journal:

Go to http://ojs.calaijol.org/index.php/ijol/about/submissions 


\title{
Establishing a Vibrant Information Literacy Program in the Absence of Curriculum Mandate: A Case Study
}

\author{
Lijuan Xu \\ Lafayette College, Easton, PA, USA
}

\begin{abstract}
This article describes how the Skillman Library at Lafayette College uses internal grants to successfully integrate information literacy into upper-level courses. There is a general consensus among faculty grant recipients that integrating information literacy in their courses not only improves students' skills as consumers of information but also helps students understand how scholars have answered questions in their particular field, and how the students themselves can contribute to the creation of knowledge. Due to their positive grant course experience, faculty members continue to build information literacy in their courses and are advocates for information literacy. The grant program created a culture of information literacy at Lafayette College and led to further pedagogical and curricular changes. It has also allowed librarians to venture into new territories such as studio art and expanded our involvement from guest lecturers to co-designing and co-teaching courses.
\end{abstract}

Keywords: information literacy, pedagogy, innovation, collaboration, grant

Many institutions, including Lafayette College, do not offer credit-bearing information literacy courses or have information literacy fully incorporated into majors and programs. In spite of this, librarians can still establish a vibrant information literacy program. One approach is to use internal grants to encourage faculty members to integrate information literacy into upper level courses, a model the Skillman Library at Lafayette College has followed since 2002. This article will describe the logistics and outcomes of such a program as well as reflect on the challenges in sustaining it and share thoughts on how to move forward.

\section{INSTITUTIONAL CONTEXT}

Lafayette College is a private, liberal arts residential college with 2,400 students. Founded in 1826, it offers a bachelor of arts in thirty-seven fields and a bachelor of science in fourteen fields, including four in engineering ("Lafayette at a glance," n.d.). All first-year students are required to 
take a fall semester seminar, capped at sixteen students, that focuses on a specific topic and engages students in active learning.

Information literacy has been an integral part of the first year seminar program since the program's inception in 1992. Each first year seminar works with a designated librarian and includes at least two library sessions, through which students learn about library resources and services, and how to conduct basic research and evaluate information. In May 2011, when the College revised its core curriculum, Lafayette faculty members voted to continue their support for the integration of information literacy in the curriculum by formally adopting four information literacy outcomes that are based on the Association of College and Research Libraries ([ACRL], 2000) Information Literacy Competency Standards for Higher Education:

IL1. Identify and articulate the need for information relevant to a specific purpose or goal.

IL2. Select the most appropriate investigative methods for different information needs and develop and employ effective search strategies to locate useful information.

IL3. Evaluate information and its sources critically and incorporate selected information into personal knowledge bases and value systems.

IL4. Understand the economic, legal, and social issues surrounding the use of information and access, and use information ethically, wisely, and legally ("First year seminar library instruction," n.d.).

However, the effort to have campus-wide full integration of information literacy is largely limited to the first year seminars. To encourage faculty to integrate information literacy into their upper-level courses so that students have opportunities to develop discipline or program specific information literacy skills, the Library and the Office of the Provost started providing information literacy grants in 2002.

\section{INFORMATION LITERACY GRANTS}

Each Spring since 2002, two to four information literacy grants $(\$ 1,500$ each) are available to faculty members interested in incorporating information literacy into their upper-level courses. While the Library runs the program, the Office of the Provost provides the funding. Faculty members participate in a lunchtime presentation in the following Fall to share their grant experience with the campus community. The lunchtime program, which all new faculty members attend as a part of their orientation, is co-sponsored by the Library and the Center for the Integration of Teaching, Learning, and Scholarship (CITLS).

\section{Requirements}

Successful grant applications must meet a set of guidelines developed by the Library according to the Information Literacy Competency Standards for Higher Education (ACRL, 2000). For a course to be eligible, the faculty member must collaborate with a research and instruction librarian and include projects that require students to find, evaluate, and use information throughout the semester. In addition, they need to incorporate projects that would help students do at least one of the following: 
- Discover that the information they use exists within a framework developed to record, store, and access it and that research allows them to tap into an ongoing conversation among scholars;

- Critically examine the research process;

- Explore the economic, social, legal, and ethical issues surrounding information in today's society ("Information literacy grants," 2017).

Faculty members can apply for and receive only one grant. The ultimate goal of the program is that once the faculty members have received a grant and incorporate information literacy work in a course, they will build information literacy into their other courses. To ensure the continuity of the program, the grants are not available to visiting or adjunct faculty members.

\section{Process}

At the beginning of each Fall semester, the Office of the Provost emails all faculty members about the information literacy grant program, soliciting grant applications. The grant information is also included on the list of available funding opportunities that the Office of the Provost maintains and shares with the faculty members every year. Faculty members have till the end of the Fall semester to turn in their grant proposals. As suggested in the call for proposals, any faculty member who is interested in applying is encouraged to meet with the Associate Director of Research and Instructional Services to discuss their ideas before submitting their applications.

Such early conversations serve as the initial screening of potential grant proposals. They help gauge a faculty member's commitment to building information literacy into their courses and, more importantly, to make sure that they understand and are prepared to implement the grant criteria. During these meetings, the faculty member and the Associate Director of Research and Instructional Services discuss the learning outcomes and goals for the proposed course and whether it would be a good fit for information literacy. Sometimes as a result of this conversation, the faculty member switches to a different course to apply for the grant application. If the course was taught before, the faculty member explains how it is going to be different from its previous nongrant funded version. This leads naturally to conversations regarding assignments and the amount of class time the faculty member intends to set aside for information literacy-related work. What kinds of information literacy projects might be appropriate as well as how to sequence them so that students can build up the skills needed for the successful completion of their final projects are also discussed.

Integrating information literacy into a course will inevitably take time away from covering content. Once the grant is in place, the Library does not have any mechanism to ensure that each recipient follows through. It is therefore important to raise issues such as time commitment and the balance between content and skills at the planning stage. Faculty members need to be aware of the potential conflict so that when pressed for time, they will not treat the information literacy component as expendable. If a faculty member feels they are not ready for the full-scale integration of information literacy, they can still work with a librarian without a grant.

Based on these discussions, faculty members send in draft proposals for feedback. After incorporating suggestions, faculty members then submit their final proposals, outlining what information literacy component(s) they intend to address in their proposed course and how. The 
one- to two-page proposals are fairly informal. The faculty member can work out the details with the designated librarian once the grant has been awarded. After discussing the final applications with the Research and Instruction team and recruiting librarians for the courses, the Associate Director of Research and Instructional Services recommends the successful proposals to the Provost, who, along with the Dean of Faculty, then approves them and sends each faculty member a formal letter confirming the decision. The letter, copied to the relevant department head, reiterates the work that the grant entails.

\section{Outcomes, Assessment, and Reflections}

\section{Recipients and Assignments}

Since the beginning of the grant program, thirty-seven faculty members from various disciplines have received an information literacy grant. Among them, eight are full or associate professors. The majority are tenure-track assistant professors. Here is a breakdown of the grant recipients by discipline:

- Eleven from the humanities: English, Spanish, Art, Music, Philosophy, and Religious Studies

- Ten from the social sciences: Anthropology and Sociology, Economics, Government and Law, and History

- Ten from interdisciplinary programs: Environmental Studies, Engineering Studies, Film and Media Studies, International Affairs, Values and Science / Technology, and Women and Gender Studies

- Four from the sciences: Biology, Chemistry, Computer Science, and Geology

- Two from engineering: Civil Engineering and Mechanical Engineering

While some faculty members use the grant as an opportunity to revamp their existing courses, others use it to design new courses. Most of the faculty members focus on helping students understand how scholarship takes place within a context so that students can situate their research in existing debates and organize previous scholarship for their own arguments. This effort is often combined with having students examine their own research process, for example, keep a journal to document and reflect on the different stages of their process, or interview experts about how they conduct research. Class information literacy projects include:

- Summarizing assigned readings and assessing the arguments against their source base;

- Analyzing different disciplinary views on a topic presented in the sources and how and why they differ;

- Submitting a "shelfie" photo with a book in the stacks and having a subsequent class discussion on the research process;

- Using concept mapping to refine topics and develop research questions;

- Identifying an article's contribution to the ongoing scholarly conversation and finding out how the article has been received since its publication;

- Following the source or data trail of a reading. 
These exercises culminate in the end of the semester research project, whether it is an annotated bibliography, a literature review, a standard research paper, a research design, or a National Science Foundation style grant proposal ("Information literacy grant recipients," 2017).

\section{Assessment and Reflections}

As mentioned earlier, the goal for the grant program is to have faculty members become interested in information literacy and teach discipline specific information literacy skills with the grant, and subsequent courses without it. Therefore, students' information literacy skills across grant-funded courses are not assessed. The courses' differences in disciplines, levels, projects, focus, and learning goals also pose special challenges for assessment. For individual courses, since information literacy is fully integrated into the course, the faculty member and the librarian rely on information literacy-related discussions, projects, presentations, and reflections to evaluate students' learning outcomes. Some courses have incorporated information literacy-related questions in students' mid-term evaluations to gauge students' progress.

\section{Grant Recipients' Perspective}

Grant recipients have many opportunities to reflect on their grant courses and offer feedback. They participate in a lunchtime panel presentation in the following Fall to discuss with the campus community their grant experience, including what worked in their courses and what challenges they encountered. In 2006, the Associate Director of Research and Instructional Services conducted individual interviews with the grant recipients still teaching at the College, collecting feedback on their information literacy experience and whether they were continuing information literacy effort in their courses. Starting in Fall 2008, feature interviews with grant recipients are published the library's bi-annual newsletter and web site. Such formal and other informal conversations (e.g., updates from the class librarian) help gauge the success of the grant courses.

Overall, faculty members are overwhelmingly positive about their grant course experience: they were able to accomplish what they planned to do in their grant proposals and were overall pleased with the quality of students' projects. There is a general consensus among grant recipients that the integration of information literacy not only greatly improved students' skills as consumers of information but also helped them understand how scholars have answered questions in their particular field and how they themselves can contribute to the creation of knowledge.

In addition to using the grant as an opportunity to address concerns they had for students and their research skills, faculty members also took it as a chance to enhance their courses and improve their pedagogy with the help of a librarian (Barnhart-Park \& Carpenter, 2002). In their lunchtime presentations and interviews, grant recipients all spoke about the importance of collaborating with a librarian to teach information literacy and attributed the success in their grant courses to the librarian's involvement. As one faculty member put it, simply going through the process - discussing her ideas with librarians and preparing her grant application-improved her course (A. Armstrong, personal communication, November 17, 2016). Many remarked on how important it is to have a librarian whom they could turn to for support during the semester to discuss the classes and assignments. Having the librarian join the classes also helps the faculty members reflect on their teaching. The opportunity to collaborate with a librarian to improve their 
courses has consequently become one of the primary reasons to apply for an information literacy grant.

Motivated by their success, most of the grant recipients continue to build information literacy into their courses. For some, information literacy has simply become "a way of thinking" (C. Phillips, 2011) and shapes how they approach the design of their courses and assignments. As one faculty member remarks, what he did in his grant course extends to his other courses (B. Hendrickson, 2014). Another agrees, "I do not see how I can go back to my old way of teaching" (N. Gil, 2015). He now incorporates information literacy into all his courses.

Grant recipients have also become information literacy advocates, both on campus and outside the College. Their advocacy has helped generate more awareness and interest among other faculty members in the grant program, and in working with librarians to improve their courses. For example, three people from the same faculty member cohort ended up applying for and receiving a grant in three consecutive years. As a result of the work by one biology faculty member in a 200-level neuroanatomy class, information literacy is now part of the general introduction to biology course. Grant recipients in Biology, English, and History have initiated conversations within their respective departments to discuss how to build information literacy into majors and so far the History Department has formally adopted information literacy into its curriculum. Recipients and their librarian collaborators have also presented at conferences and helped other schools (e.g. Brandeis University and Trinity University) to develop their information literacy program.

\section{Librarians' Perspective}

From the librarians' perspective, being involved in the design and development of the course syllabi and assignments, makes the experience much more meaningful than that with non-grant courses. The librarians also teach designated information literacy sessions and meet with students individually about their projects. When schedules permit, librarians attend regular classes and participate in class discussions. In some courses, librarians are regarded as co-teachers (Xu \& Gil, 2017). Being embedded in the course or co-teaching the course not only raises the profile and presence of the Library and the librarian, but also makes the approach to information literacy more organic in that it allows librarians to follow students' progress and address any research-related questions as they arise. Having learned about the benefits of this model, some faculty members specifically request that librarians embed in their courses.

One benefit that faculty members stress about having librarians in their classes is that it helps faculty members become better teachers. Likewise, librarians' teaching skills have improved from watching faculty members teach. In addition, regularly attending the classes helps librarians gain subject knowledge and become familiar with the research practices in a particular field. This in turn enables these librarians to better help students in the grant course, in other courses, and at the research help desk. Despite the small size of the College, faculty members might not be aware of their colleagues' research interests and pedagogical practice. Since librarians work closely with classes of all levels and from various disciplines and also provide opportunities for faculty members to share their grant experience, librarians become intermediaries that connect faculty members from different disciplines, thus fostering cross-campus collaborations. 


\section{Challenges and Next Steps}

One challenge in running the grant program is librarian workload. This issue will become more pressing as more faculty members collaborate with librarians and the College expands. How do librarians keep doing their best work and continue to sustain the program in the long run? While librarians continue to work with faculty members with or without a grant, they will also need to explore programs that would complement their effort. The "What's your favorite writing assignment?" faculty member panel presentation is a good example. Co-sponsored by the Library, CITLS, and the College Writing Program (CWP), this panel provides an opportunity to discuss alternative research assignments that promote critical thinking.

The discipline breakdown of grant recipients indicates a lag in services to natural sciences and engineering with four and two recipients respectively. This spring, librarians are working with a chemistry professor on a grant course. The professor's input and feedback will be crucial to the Library. Librarians have also made progress this semester with the Computer Science Department through work with a computer science writing course on issues related to "fake news", search algorithm biases, open source development, etc. Further conversations will need to take place among librarians on how to continue and expand this kind of work.

Despite its disadvantages, the person-specific model for the grants also means that grant recipients are teaching various levels of courses and could play important roles in the College's curriculum in their capacity as a department head, CITLS director, and first year seminar program coordinator. With this year's first year seminar information literacy assessment results, the first year seminar program coordinator, the CWP director, and the Associate Director of Research and Instructional Services have discussed how information literacy, like writing, needs to be integrated into the college's four-year curriculum. This information was included in the information literacy assessment report and will be emphasized when the assessment results are shared with the campus at a presentation in Fall 2017.

The Library can start approaching departments that have multiple grant recipients to discuss how to build on information literacy sequentially through the years. This would help address the repetition and overlap issue when courses from the same department or program incorporate information literacy. It would also provide a welcome opportunity for librarians to revisit the grant guidelines in light of the Framework for Information Literacy for Higher Education (ACRL, 2016).

\section{CONCLUSION}

Using information literacy grants allows librarians to successfully integrate information literacy into many upper-level courses and to play a more meaningful teaching role. It has also created a fortunate cumulative effect since grant recipients continue information literacy work in their other courses. The impact of the grant program extends further to other faculty members and their courses since grant recipients formally and informally share their experience with colleagues. As a result, the grant program has resulted in a culture of information literacy on our campus and has led to further pedagogical and curricular changes. Although librarians have been able to achieve systematic and full curriculum integration of information literacy in only one department, the grant 
program has generated more awareness of and interest in the importance of information literacy and what librarians can do.

\section{ACKNOWLEDGEMENTS}

The author would like to thank the Office of the Provost for funding the grant program, Terese Heidenwolf for her leadership and for getting the program started, many faculty members for their advocacy and support, and the library colleagues, whose contributions make the success of the program possible.

\section{References}

Association of College and Research Libraries. (2000). Information literacy competency standards for higher education. Retrieved from http://www.ala.org/acrl/sites/ala.org.acrl/files/content/standards/standards.pdf

Association of College and Research Libraries. (2016). Framework for information literacy for higher education. Retrieved from http://www.ala.org/acrl/sites/ala.org.acrl/files/content/issues/infolit/Framework_ILHE.pdf

Barnhart-Park, A.C., \& Carpenter, W.J. (2002). Information literacy and literary questions. Academic Exchange Quarterly, 6(4), 10-16

First year seminar library instruction. (n.d.). Retrieved from https://library.lafayette.edu/services-help/services/instruction-and-informationliteracy/first-year-seminar-library-instruction/

Gil, N. (January 2015). Interview with Nestor Gil. Retrieved from https://library.lafayette.edu/people/nestor-gil/

Hendrickson, B. (January 2014). Interview with Brett Hendrickson. Retrieved from https://library.lafayette.edu/people/brett-hendrickson/

Information literacy grants. (2017, January 5). Retrieved from https://library.lafayette.edu/services-help/services/instruction-and-informationliteracy/information-literacy-grants/

Information literacy grant recipients. (2017, January 5). Retrieved from https://library.lafayette.edu/services-help/services/instruction-and-informationliteracy/information-literacy-grant-recipients/

Lafayette at a glance. (n.d.). Retrieved https://about.lafayette.edu/lafayette-at-a-glance/ Phillips, C. (January 2011). Interview with Chris Phillips. Retrieved from https://library.lafayette.edu/people/chris-phillips/

Xu, L., \& Gil, N. (2017). Librarians as co-teachers and curators: integrating information literacy in a studio art course at a liberal arts college. Art Documentation: Journal of the Art Libraries Society of North America, 36 (1), 122-136.

\section{About the author}

Lijuan $\mathrm{Xu}$ is the Associate Director of Research \& Instructional Services at Lafayette College, Easton, PA. 